\title{
"UMA GAVETA MAIS PÚBLICA": A BLOGOSFERA COMO ESPAÇO COLECTIVO DE PRÁTICAS SOCIO-POÉTICAS
}

\author{
Rita Grácio \\ Universidade Lusófona, Lisboa \& CES-UC, Coimbra, Portugal ${ }^{1}$
}

\begin{abstract}
Entendendo a blogosfera como um espaço colectivo de práticas socio-poéticas, propóe-se uma análise empirica do uso dos blogs por poetas amadorxs. A poesia como mundo da arte colectivo é operacionalizada através do estudo qualitativo das redes sociais [Qualitative Social Network Analysis] (Heath, Fuller, e Johnston 2009; Portugal 2006) destes poetas amadorxs. Foram realizadas entrevistas a catorze pessoas que mantinham um blog contendo poemas "experimentais" (afastados da tradição lírica/confessional do cânone poético português). Os blogs vêm alargar as redes sociais destxs poetas-bloggers, através de novos nós e laços, e da reterritorialização de nós e laços offline. A blogosfera mimetiza e amplifica alguns aspectos de espaços colectivos offline (eg: revistas, grupos), mas com singularidades que derivam das suas possibilidades sociotécnicas. A blogosfera é permeada de tensões quanto à autorialautoridade literária, em relação com os velhos media. O blog tem implicações na produção, distribuição e consumo de poesia, que este artigo discute.
\end{abstract}

Palavras-chave: poetas amadores, blogosfera, blogs de poesia, novos media, colectivos, análise qualitativa de redes sociais

1 Centro de Investigação em Comunicação Aplicada, Cultura e Novas Tecnologias (CICANT) e Centro de Estudos Sociais da Universidade de Coimbra. A autora agradece os comentários da revisão por pares, que muito contribuiram para melhorar o artigo. A autora agradece a Sílvia Portugal, pelo constante e frutífero debate sociológico e partilha, a Graça Capinha, investigadora responsável do projecto "Novas poéticas" (FCOMP-01-0124FEDER-007264), e a todxs xs poetas experimentais. O artigo é da inteira responsabilidade da autora. Contacto: rita.gracio.alberto@gmail.com 


\section{A BLOGOSFERA COMO ESPAÇO COLECTIVO PARA PRÁTICAS SOCIO-POÉTICAS}

A poesia, como qualquer outro "mundo da arte" (Becker 1992:13), envolve a acção conjunta de um grupo de pessoas. Logo, a poesia é uma actividade colectiva.

As sociologias da arte têm demonstrado isso mesmo, especificando a importância de vários atores no mundo/campo artístico, ao nível das carreiras artísticas, do estabelecimento de convenções (Becker 1992), e da atribuição do valor e sentido na obra de arte (Bourdieu 1996). Embora a poesia tenha sido uma das formas artísticas menos estudadas pela sociologia e antropologia da arte e da cultura (Griswold 1993), tem havido um crescente interesse neste objecto de estudo pelas ciências sociais, cuja agenda de investigação privilegia a dimensão colectiva do fazer poético (Craig e Dubois 2010; Craith e Fournier 2016; Gregory 2015). No entanto, a sociologia da literatura tem-se focado nos actores dos mundos da arte em si, prestando menos atenção ao papel dos outros significativos implicados no mundo da arte - pais, amigos, colegas e, mesmo, estranhos. Estes agentes são fundamentais nas trajectórias artísticas, sobretudo para artistas amadores (Craig 2006; Finnegan 2007), incluindo poetas.

Poetas são aqui entendidos como amadores, na senda de Hennion (2001), que explora, em francês, o duplo sentido semântico de amateurs. Assim, poetas amadores são praticantes activos do amor pela poesia, que toma a forma de escrita de poemas; mas são também não-profissionais - à margem, mas em relação, com os actores e as instituições literárias dominantes e com os mecanismos institucionalizados de consagração (currículos escolares e universitários definidos por académicos, os media e os críticos literários, o mercado editorial e livreiro, prémios literários e associações de escritores (George 2002).

Os blogs e a blogosfera (designação do conjunto de blogs), surgidos nos anos 1990, são uma das mais antigas tecnologias da chamada web 2.0., a par de wikis e redes sociais. Levinson (2012) argumenta que estes novos media são de facto "novos novos media", com semelhanças e diferenças em relação aos "novos media" (dominados pelas corporações) e "velhos media" (rádio, televisão e meio impresso). Xs leitorxs deixam de ser merxs consumidorxs, pois a qualquer momento, podem tornar-se (co)autores. É a isto que se refere também Jenkins (2006) quando fala dos blogs como um media de "cultura participativa", que desfaz a rígida fronteira entre produtores e consumidores.

A história da blogosfera é marcada pelo jornalismo e pela política, mas os blogs podem ser sobre qualquer assunto, e a literatura é um deles. No entanto, poucos têm sido os estudos sobre a blogosfera literária, com raríssimas excepções (Gijón 2013).

Este artigo pretende contribuir para expandir o corpo de estudos sobre a literatura e os novos media, através da análise empírica do impacto dos blogs nos modos de produção, distribuição e consumo poético.

Sendo a poesia colectiva, e a blogosfera um "novo novo media", marcada por uma cultura participativa, a blogosfera poética será, inevitavelmente, um espaço colectivo participativo.

Para perceber a blogosfera poética analisei o uso dos blogs por poetas amadores, que é condicionado pelas especificidades sociotécnicas desta plataforma digital, que apresento na secção 2, contextualizando a blogosfera poética. Para operacionalizar o estudo da poesia como 
colectiva, quer online, quer offline, uso uma abordagem qualitativa da teoria das redes sociais, que explico na secção 3. De seguida, faço uma caracterização dxs catorze poetas que entrevistei (secção 4). Para perceber o impacto do blog na criação, distribuição e consumo de poesia, é importante perceber quais as redes sociais destxs catorze poetas, antes e depois da criação do blog. Por isso, na secção 5 apresento as redes sociais dxs poetas amadores antes da criação do blog, e na secção 6 a reconfiguração das redes sociais proporcionadas pelo blog. Na secção 7 apresento algumas reflexões finais.

\section{POESIA EM PLATAFORMAS DIGITAIS: A BLOGOSFERA POÉTICA COMO UM ESPAÇO ONLINE COLECTIVO}

O blog (diminutivo de web log) é, sobretudo, uma forma de publicação online. A pessoa que escreve um blog designa-se por blogger (pode escolher ser anónima). A blogosfera é a designação do conjunto de blogs. Pode ser criado um blog em diferentes plataformas digitais, a um custo virtualmente zero, já que a maioria das plataformas são gratuitas (e.g.: Blogger, Blogspot, Wordpress), e exigem poucos conhecimentos técnicos.

Cada mensagem ou entrada que se publica no blog é um post. Os posts estão quase sempre organizados cronologicamente, com os posts mais recentes a figurar na parte de cima do blog. $\mathrm{O}$ blog permite o arquivo (e a edição) de cada post. $\mathrm{O}$ blog permite também ter uma lista de outros blogs e websites favoritos. Os posts são sobretudo textos, mas podem ser também outros elementos semióticos, tais como imagens, som e vídeo e/ou byperlinks, que contribuem para expandir as possibilidades de leituras, sendo uma das características da blogosfera a hibridização dos sistemas semióticos (Babo 2000:2).

Os blogs têm ainda uma importante ferramenta interactiva, o comentário, que permite que visitantes do blog possam publicar um comentário em "resposta" a cada um dos posts, e que, depois de publicado, fica visível para qualquer visitante do blog. É também possível comentar os comentários. Todos os comentários estão agrupados na secção "caixa de comentários", que fica organizada cronológicamente do comentário mais recente para o mais antigo. São xs bloggers que decidem se essa ferramenta fica activa ou não, controlando a possibilidade de xs visitantes deixarem comentários ou não.

Por isto Levinson considera a blogosfera um "novo novo media". Por oposição aos "novos media", dominados por corporações, os "novos novos media" dão às pessoas um grande poder e liberdade, pois, a qualquer momento, qualquer pessoa (consumidor) pode tornar-se produtor/ criador. A mudança de estatuto de consumidor para produtor pode ser feita individualmente (e.g.: criar um blog, ou fazer um comentário num blog), ou em grupo, já que um blog pode ser escrito por mais que um autor. É a isto que se refere Jenkins (2006) quando fala dos blogs como um media de "cultura participativa" que desfaz a rígida fronteira entre produtores e consumidores, sendo que estes últimos passam a ser encarados como agentes, que, no entanto, reconhece Jenkins, não têm todos o mesmo estatuto, nem o mesmo poder - as corporações têm mais poder que os indivíduos (Jenkins 2006:3)

É importante fazer uma brevíssima contextualização da blogofera portuguesa, no âmbito de uma ecologia mediática internacional. Enquanto o boom da blogosfera norte-americana se 
desencadeou na sequência do 11 de Setembro e da posterior invasão do Iraque pelos Estados Unidos, tendo tido a blogosfera norte-americana grande visibilidade como fonte de notícias alternativas (Herring et al. 2005), o boom da blogosfera portuguesa desencadeia-se em 2003, pela colonização deste meio por políticos, jornalistas e "homens de letras" mediáticos que assim dominaram o espaço e os temas da blogosfera (Granado e Barbosa 2004).

Assim, a blogosfera (e o seu estudo) tem sido sobretudo sobre jornalismo e política, embora os blogs possam ser usados como ferramentas de publicação online sobre qualquer assunto, incluindo literatura e poesia. Defende Babo que há uma resistência das elites à escrita online, e que "a crise da escrita como instituição literária passa aqui também pela abolição dos seus rituais que contribuíam para essa institucionalização" (2000: 6). Num dossier sobre revistas literárias (subentenda-se, impressas) publicado na revista Callema, a teórica Emília Pinto de Almeida concede um parágrafo do seu ensaio para comparar blogs e revistas online com as revistas impressas, apontando a falha (sic) das primeiras: "embora o blog tenha incorporado uma série de aspectos que definiam a revista modernista, muito em particular, como a discussão de ideias, a polémica e até a combatividade, o sentido de grupo ou a possibilidade de uma intervenção imediata pela facilidade de publicação e ausência de mediação, não se constitui como objecto [tipo(gráfico)]". O blog é apresentado como um meio neutro, enquanto a revista em papel enquanto meio é sempre considerada na sua qualidade de objecto. Várias potencialidades da hiperedição são enumeradas, para serem depois vetadas ao desinteresse pela ausência de materialidade - como se a hiperedição não tivesse forma, e o digital fosse imaterial.

Xs poetas amadores em Portugal reapropriaram esta plataforma digital como forma de auto-hiperedição literária (Portela e Grácio 2012), criando e mantendo blogs cujo conteúdo principal são poemas da sua autoria. Por causa das possibilidades sociotécnicas do blog, este é mais do que um "livro transposto" em meio digital. Isto porque as ferramentas interactivas permitem usos e interações específicas com o conteúdo (muitas vezes não só textual, mas multimédia), quer da parte de poetas, quer da parte de visitantes, que não seriam possíveis num livro impresso.

Depois do boom da blogosfera, nos inícios de 2000, os blogs têm vindo a decrescer (Levinson, 2012: 7), comparativamente com o crescimento de redes sociais. Isto reflecte-se também nos trabalhos académicos, que vão acompanhando o estudo das plataformas digitais mais recentes. Assim, este artigo pretende dar conta de um momento específico na história (ou na "arqueologia") dos "novos novos media" na sua relação com a prática poética. Pretende-se retratar um período muito dinâmico da blogosfera em Portugal (2003-2010), antes do boom de outras redes sociais, como o Facebook (lançado em Portugal em 2008) ou, mais recentemente, o Instagram e o Twitter. Embora uma análise da relação entre o blog e estas novas plataformas, bem como do seu impacto nos mundos da poesia fique fora do âmbito deste artigo, este é certamente um tema de investigação futura (de que é exemplo o colóquio "Reading \#Instapoetry"2).

2 Conferência na Universidade de Glasgow, em 2020: http://saesfrance.org/may-27th-2020-reading-instapoetry-university-of-glasgow/ 


\section{A POESIA COMO ACTIVIDADE COLECTIVA OPERACIONALIZADA ATRAVÉS DA ABORDAGEM QUALITATIVA DA TEORIA DAS REDES SOCIAIS}

Para a Teoria das Redes Sociais (TRS), “as estruturas sociais podem ser representadas como redes - como conjunto de nós (...) e conjuntos de laços que representam as suas interconexões. (. . .) Os "laços" são usados para representar fluxos de recursos, relações simétricas [e, acrescento, assimétricas] de amizade, transferências, ou relações estruturais entre nós" (Wellman e Berkowitz 1991:4). ${ }^{3}$

Embora a maioria dos estudos de TRS seja quantitativo, tem vindo a aumentar a aplicação de metodologias qualitativas ao estudo das redes sociais, que permitem dar mais atenção ao carácter processual e dinâmico das redes. E, de facto, a metáfora do social como rede está enraízada na tradição sociológica alemã interpretativista, sobretudo em Simmel, mas também em Weber e Tönnies (Scott 1991).

Assim optei por uma abordagem qualitativa da Teoria das Redes Sociais (Qualitative Social Network Analysis), que descreve a morfologia e conteúdo das redes (nós e laços). Embora a TRS contemple apenas nós humanos, optei por integrar nós não-humanos, como o blog e o livro, na esteira da Actor Network Theory (ANT), que analisa a agência de elementos não-humanos (Latour 2005). Esta opção afigura-se como a ferramenta teórica adequada para visibilizar os humanos e não-humanos que constituem a rede de relações sociais de poetas amadorxs ${ }^{4}$. Permite ainda perceber que tipo de influência estes exercem nas identidades e trajectórias artísticas destxs poetas, na sua escrita e prática poética, e em que fases das suas trajectórias. Este tipo de informação, por ser, muitas vezes, intangível, poderia não chegar a ser articulado - uma vantagem que tem sido descrita por outros estudos qualitatitivos da teoria das redes sociais (Heath et al.2009). A abordagem qualitativa da TRS permite ainda dar conta da diversidade das esferas e dos backgrounds sociais desses vários nós nas redes (Heath et al. 2009: 648).

Aplicando a teoria das redes à análise da arte, a vantagem é mostrar como as trajectórias e identidades artísticas não são totalmente determinadas pelas posições dos indivíduos no campo e seus habitus (Bourdieu 1996), nem pelo talento individual (DeNora 1995). Identidades e trajectórias são mediadas pelos actantes na rede social dxs poetas, e pelo acesso aos recursos que esses actantes facilitam ou constrangem. A partir de uma abordagem qualitativa e egocentrada, considero que cada poeta-blogger é um "ego" que nomeia os "nós" com quem estabelece "laços". Ao permitir o estudo dos laços que se estabelecem entre o "ego" e os outros nós da rede, a QSNA foca-se nas relações (e.g.: relações poeta-poeta, poeta-leitor, poeta-ídolo literário), ao mesmo tempo que permite situar essas relações na rede - na rede como um todo, ou em partes específicas da rede (online, offline, literárias, familiares...) (cf. Heath et al, 2009: 648).

Sigo a operacionalização do conceito de rede social proposta por Sílvia Portugal para o estudo das relações familiares, a partir de duas questões: quem faz parte da rede? Quais os conteúdos dos fluxos que circulam no interior da rede? Desta forma, descrevo a morfologia e o conteúdo das redes sociais destxs poetas amadores, antes e depois da criação do blog.

\footnotetext{
3 As citações traduzidas são da responsabilidade da autora.

4 de Nooy (2003) usou a abordagem quantitativa da TRS (numa perspectiva enformada pelo campo de Bourdieu) para estudar as redes de escritorxs, criticxs e revistas literárias holandeses, mas não contemplou agentes “para-artísticos”, como família e amizades.
} 
As propriedades dos laços, nomeadamente o sentido e a força dos laços, permitem perceber o acesso aos diferentes recursos. Quanto ao sentido, os laços podem ser positivos, negativos, mistos ou neutros. Os laços positivos são laços de identificação através dos quais os actores sociais se consideram membros de um colectivo (com quem me identifico?); os laços negativos são laços de diferenciação, que fazem os indivíduos distinguirem-se de "outros" (e definem os limites, a fronteira das redes). Os laços mistos são os que envolvem laços positivos e negativos; e os laços neutros são laços de indiferença (Portugal 2006: 24).

Quanto à força, os laços podem ser fortes ou fracos. Granovetter (1973) caracteriza os laços quanto à duração, intensidade emocional, intimidade e serviços recíprocos. Os nós com quem se passa mais tempo, com quem se tem uma relação emocional mais forte, com quem existe relação de intimidade e com quem se trocam serviços são aqueles com os quais se estabelece laços fortes. A negação, ou a menor intensidade destes pressupostos, dá-nos os laços fracos. Há ainda laços activos e passivos: os primeiros tomam a forma de ajuda directa (com quem estou no quotidiano e interajo face a face) e os segundos referem-se às pessoas (ou outros nós) com quem não se interage frequentemente, mas com quem se tem uma relação afectiva (normalmente são amigos e família distante).

A resposta à pergunta "o quê?" permite perceber o conteúdo das redes, ou seja, os tipos de recursos que circulam nas redes sociais. Neste caso, o conteúdo pode passar pela informação sobre o aparecimento de oportunidades literárias (o aparecimento ou conhecimento de uma revista, um concurso literário, uma nova editora, um encontro de escritores...), pode passar pelo convite directo à publicação (em revista, antologia, editora, blog), ou pode passar pela facilidade da participação (em encontros de escritores, lançamentos de livros, convívios sociais entre escritores, entrevistas em meios de comunicação).

\begin{tabular}{|l|l|l|}
\hline Propriedade & \multicolumn{1}{|c|}{ Definição } & \multicolumn{1}{c|}{ Indicadores } \\
\hline & & Apoio material \\
& & Apoio financeiro \\
& & Apoio em serviços \\
& & Suporte afectivo \\
& & Sociabilidade \\
& & Informação \\
Conteúdo & Tipo de recursos que circulam & Incentivo \\
& entre X e Y & Motivação \\
& & Reconhecimento Literário \\
& & Oportunidade Literária \\
& & Feedback \\
& & Feedback (troca e-mails) \\
& & Link \\
& & Visita \\
\hline \multirow{3}{*}{ Força } & & Comentário \\
& & Interesses \\
\hline & & Influência nas escolhas e decisões: \\
& & 1. motivação/gosto pela escrita \\
& & 2. na escrita em si \\
& & 3. no reconhecimento \\
& & 4. no blog \\
\hline
\end{tabular}

Tabela 1- Propriedades dos laços - caracterização dos laços e dos seus fluxos 
Os indicadores, utilizados para caracterizar os laços e os fluxos por eles gerados, estão representados na tabela 1 . De seguida, apresento as opções metodológicas e os resultados empíricos.

\section{Poetas AmadorXs e Bloggers}

Foram realizadas entrevistas abertas, em profundidade, a catorze poetas amadorxs e bloggers, cuja caracterização é apresentada abaixo. As entrevistas foram realizadas entre 2008 e 2009 (ver tabela 2).

\begin{tabular}{|c|c|c|c|c|}
\hline Nome & Género & Grupo etário & Ano nascimento & Habilitações \\
\hline Raquel & $\mathrm{F}$ & \multirow{7}{*}{ 18-34 anos } & 1982 & Licenciatura \\
\hline Ana & $\mathrm{F}$ & & 1983 & Licenciatura \\
\hline Sofia & $\mathrm{F}$ & & 1976 & Licenciatura \\
\hline Eduardo & M & & 1983 & Licenciatura \\
\hline Paulo & M & & 1981 & Mestrado (área de Literatura) \\
\hline Álvaro & M & & 1979 & Licenciatura \\
\hline Afonso & M & & 1982 & Licenciatura (área de Literatura) \\
\hline Diana & $\mathrm{F}$ & \multirow{2}{*}{$35-44$ anos } & 1972 & Licenciatura (área de Literatura) \\
\hline Mariana & $\mathrm{F}$ & & 1969 & Licenciatura (área de Letras) \\
\hline Liliana & $\mathrm{F}$ & \multirow{5}{*}{45 anos ou mais } & 1955 & Licenciatura \\
\hline Joana & $\mathrm{F}$ & & 1964 & Licenciatura \\
\hline Artur & M & & 1957 & Licenciatura - a frequentar (área de Literatura) \\
\hline Rui & M & & 1953 & Doutoramento \\
\hline Hélder & M & & 1961 & $12^{\circ}$ ano \\
\hline
\end{tabular}

Tabela 2 - Caracterização dxs entrevistadxs de acordo com género, ano de nascimento e habilitações académicas

Entrevistei catorze pessoas, sete homens e sete mulheres, distribuídos por três grupos etários (18-34 anos, 35-44 anos e a partir dos 45). Tentei diversificar a localização geográfica, mas o conjunto dxs entrevistadxs acabou por se concentrar no distrito de Lisboa. A maioria tinha, pelo menos, uma licenciatura completa (e quatro tinham formação específica na área de Literatura), com excepção de dois entrevistados: um tinha o $12^{\circ}$ ano e o outro encontrava-se a frequentar a licenciatura (na área de Literatura). Há uma sobrerepresentação de indivíduos com níveis de escolaridade mais elevados, e no distrito de Lisboa, o que provavelmente se prende com questões de desigualdade no acesso à Internet e a computadores pessoais.

A selecção de pessoas a entrevistar cruzou uma preocupação com a diversificação de variáveis sociográficas (género, idade, nível de escolaridade, profissão, localização geográfica), bem como critérios literários. Escolhi estas pessoas a partir dos poemas publicados nos seus blogs.

O cânone poético que se transmite nas escolas portuguesas pós-25 de Abril, através dos programas e manuais da disciplina de Português, tem sido consensual ao logo do tempo, dos quais são expoente máximo Luís de Camões e Fernando Pessoa (Dionísio e Castro 
2005; Ramalho 1994). Sendo o ensino obrigatório até ao $12^{\circ}$ ano, abrangendo a disciplina de Português, considero que são sobretudo os curricula escolares que formam um entendimento partilhado popular sobre o que é poesia e qualidade poética.

Deste modo, procurei poemas que se afastassem da tradição literária ensinada nas escolas, seleccionando poemas não líricos e não confessionais, e também afastados do realismo social e da poesia engagada. Poemas que designei "experimentais". O corpus de análise é constituído por poesia "contra-hegemónica" em relação à hegemonia socio-poética do canône literário português, transmitido nas escolas.

A partir dos elementos estruturantes do guião da entrevista, desenvolvi uma análise temática das entrevistas, em que os indicadores das propriedades dos laços dxs entrevistadxs foram tidos em conta, bem como uma análise horizontal que permitiu a comparação das entrevistas. $\mathrm{O}$ objectivo das secções seguintes é desenhar a rede social destxs poetas amadores, antes e depois da criação do blog. A partir da análise da poesia como actividade colectiva, discuto as especificidades da blogosfera poética como actividade colectiva, em relação com o "cânone", nas reflexões finais.

\section{NóS E LAÇOS DA REDE SOCIAL DXS POETAS AMADORXS ANTES DA CRIAÇÃO DO BLOG}

Até ao momento de criação do blog, os nós identificados como mais significativos na construção das identidades poéticas são a família (pais, irmãos, avós, primos), ${ }^{5}$ professorxs, amigxs e colegas. São nós com quem, na maioria das vezes, se estabelecem laços positivos e fortes e onde circulam afectos e sociabilidades, bem como incentivo, e que influenciam fortemente a motivação e o gosto para a "escrileitura". Associado a estas figuras, ou como acto autónomo, aparece o acto de leitura, que assume protagonismo, correspondendo muitas vezes ao próprio interesse pela escrita.

No entanto, os laços de parentesco também se podem constituir como laços negativos em fases mais tardias das trajectórias poéticas (são os casos de Hélder, Liliana e Artur, cujas famílias desincentivaram à publicação e a seguir carreiras de escritor/a).

A referência a livros (situados em bibliotecas) levou-me a encará-los também como um nó, com quem estabelecem laços positivos. Quer em contextos familiares favoráveis (biblioteca própria), quer em contextos familiares desfavoráveis ${ }^{6}$ (como nos caso de Álvaro e Raquel, que, na sua infância dos anos 80 e 90, liam os livros da biblioteca enquanto guardavam vacas).

Xs professorxs ${ }^{7}$ potenciam ou inauguram a motivação para a escrita, acrescentando-lhe feedback e proporcionando as primeiras oportunidades literárias, oferecendo reconhecimento -

5 De notar que nenhum/a dos familiares dxs entrevistadxs tem uma ocupação directamente ligada à literatura ou a outras artes.

6 Podemos perceber a importância das políticas culturais descentralizadas (equipamentos públicos como bibliotecas) na redistribuição do acesso a bens culturais, de forma a reparar as desigualdades estruturais (ou de forma a limitar a reprodução das mesmas).

7 Saliente-se que são sobretudo professorxs do ensino obrigatório e secundário, e menos os universitários. 
já que publicam os textos dxs alunxs em publicações escolares ou enviam-nos para concursos literários.

Quanto a amigxs e colegas, as redes são de três tipos: constituídas por pessoas que também escrevem, por pessoas que não escrevem, e redes constituídas por pessoas que escrevem e que não escrevem. Amigxs que não escrevem podem dar incentivo, até algum feedback, e reconhecem uma identidade poética aos/às amigxs que escrevem. Xs amigxs que também escrevem conhecem-se sobretudo na universidade, e em cursos de escrita criativa. E com elxs que se formam blogs literários ou com quem se conta para integrar um evento poético (workshop em escolas ou livrarias) ou projectos artísticos (filmagens para curta-metragem, exposições de poesia e fotografia) ou para escrever textos em conjunto - apoio em serviços. É com amigxs-poetas que se conversa sobre os textos poéticos (feedback); são elxs que convidam para publicar em revistas ou em editoras; para fazer leituras de poesia; são elxs que fazem recensões.

\section{A CRIAÇÃO DO BLOG E A RECONFIGURAÇÃO DOS NÓS E LAÇOS DAS REDES SOCIAIS DXS POETAS AMADORXS}

Com a criação e manutenção de um blog, a morfologia das redes sofre alterações. Surgem novos nós e laços - com outros bloggers, com leitorxs e visitantes - mas também nós e laços antigos (de amizade e de parentesco) são (re)territorializados online. Ao longo das suas trajectórias, é o blog e são os laços bloguísticos que parecem consolidar, de forma decisiva, a identidade poética. Joana fala do blog como "sítio de liberdade, onde procuro realizar-me através das formas que me estão mais próximas". Diana e Afonso falam da importância do blog no processo de auto-conhecimento (poético, identitário). Muitxs encaram o blog como uma entidade (cf. (Brown, Broderick, e Lee 2007). Para Mariana ou Hélder o blog é como "um filho", um "complemento"; para Afonso, "um bebezinho"; Eduardo diz que o blog representa "alguma intimidade por estar ali naquele espaço de corpo de texto a escrever".

\section{Des-re-territorialização: do offline para o online}

Xs amigxs (offline) são os primeiros a quem se dá a conhecer o blog ou são incentivadores da criação do blog e também ajudam tecnicamente a criar e manter o blog. Joana explica que os seus amigxs, mesmo os que também são bloggers, preferem comentar o seu blog pessoalmente, por e-mail, SMS ou telefone; e ela própria, embora visite blogs de amigxs mais que uma vez por dia, não os comenta. Este fenómeno, mencionado por Ana, Paulo e Diana, vem confirmar a hipótese de que a comunicação iniciada no blog é continuada noutros canais de comunicação, o que pode ser característico de blogs com pouco público, em que a maior parte dxs leitorxs estão na rede social offline dos bloggers, permitindo o link pessoal necessário para continuar a interacção noutros canais (Nardi, Schiano, e Gumbrecht 2004).

O blog fortalece laços de amizade e parentesco. Por exemplo, Mariana e as suas amigas decidem, no café, formar um blog juntas. No blog, postam-se fotografias feitas pelos amigos e pela família (Joana) e poemas e desenhos feitos pelos filhos (Diana) - os nós offline são re-localizados e re-significados online. 


\section{Novos territórios, novos nós}

Através do blog surgem novos nós: bloggers, leitorxs, visitantes e também ídolos. Com estes novos nós, a rede dxs poetas-bloggers alarga-se. Estes laços bloguísticos representam uma forma de angariar capital social e literário: pares, público e/ou amigxs e até ídolos-bloggers (isto é, pessoas que já eram ídolos offline e que têm blog). Designo por leitorxs as pessoas que deixam comentários (sejam bloggers, ou não) e visitantes as pessoas que apenas acedem ao blog (lurkers). Com visitantes não se estabelecem laços fortes, ${ }^{8}$ mas estabelecem-se laços positivos, dado que são encarados enquanto "comunidade imaginada" de leitorxs, "leitores fantasma" (Eduardo). Assim, a actividade de lurking não é apenas uma forma de participação legítima para lurkers (Efimova et. al, 2005), é também importante para xs bloggers.

Sobretudo para quem não tem amigxs que também escrevam em meio online, os novos nós são decisivos para a consolidação de trajectórias poéticas. Acontece com Sofia, que passou a ter comentários quando o seu blog foi divulgado por uma outra blogger; e também com Paulo, que não tinha amigxs que escrevessem e é através do blog que conhece, pessoalmente, as únicas "duas ou três pessoas que também escrevem".

\section{Alimentar, comentar e linkar: colectivos na blogosfera}

No blog, há “obrigações" e "reciprocidades". A principal obrigação que xs bloggers referem é manter o blog actualizado, "alimentar" o blog - surge a metáfora do blog como tamagotchi $i^{9}$. É uma obrigação positiva para com xs leitorxs que simultaneamente motiva xs bloggers a escrever (como um "motor", uma "mola") mas, em blogs com muito tempo de existência, esta obrigação pode tornar-se negativa (o comentário como dádiva passa a ser encarado como dívida). Quanto mais antigo é um blog de poesia, com poemas inéditos, menos frequentemente é actualizado. A actualização regular é considerada por muitos teóricos como condição do formato blog (Herring et al., 2005); contudo estxs poetas-bloggers nem sempre publicam regularmente e a irregularidade da publicação é mesmo encarada como liberdade (criativa); mas não deixam de ter leitorxs e visitantes (embora possam diminuir). Os blogs de poesia têm um ritmo próprio em relação a outros blogs, porque a escrita é trabalhada (antes de publicarem no blog, estxs poetas trabalham os textos no Word ou no papel e pedem opinião e/ou colaboração para o poema a amigxs, bloggers ou não).

Os comentários são o recurso mais importante que circula nos laços bloguisticos, fundamentais para a existência de colectivos de poetas-bloggers. ${ }^{10} \mathrm{~A}$ prática de comentar deve ser recíproca: se alguém comenta o blog, esse comentário é retribuído. Mas não basta a reciprocidade, os comentários devem ser positivos, únicos, interessantes e moderados. Mais importante do que o número de comentários, é a regularidade e o conteúdo dos mesmos que fomentam sociabilidades, inaugurando e permitindo a continuidade dos laços bloguísticos. É com xs leitorxs

$8 \quad$ Excepto quando essxs visitantes são amigxs offline.

9 O tamagotchi é um animal de estimação virtual. O tamagotchi foi lançado pela Bandai, em 1996, no Japão. O objectivo é cuidar do animal virtual como se fosse real, dando-lhe carinho, comida, banho virtual, etc. Caso contrário, esse animal cresce feio e/ou mau, e morre (virtualmente). Cf. http://www.bandai.com/support/pdfs/tama/ tama_v1.pdf

10 Várixs entrevistadxs, para além do comentário, usam o e-mail para contactar outrxs (poetas) bloggers, procurando "conhecer melhor" quem admiram. 
(que fazem comentários com estas características) que se estabelecem laços fortes, positivos e activos (online e/ou offline). As relações iniciadas através do blog podem ter continuidade face-a-face ${ }^{11}$. Mesmo que não tenham essa dimensão, "o blog é uma grande arma de criar laços", afirma Álvaro, para quem xs leitorxs são referidos como "amigos vocacionados para a leitura”; são pessoas que não se faz ideia de quem sejam, mas com quem se cria "empatia" e "amizades bloguísticas" (Diana). A quebra da prática de comentar afecta a identidade poética e bloguística"é aquele sentimento de: tu não comentas e és como que excluída, sabes? (Raquel).

O comentário nos outros blogs é regulado pela afectividade e pelo mérito. Estxs poetas-bloggers visitam e/ou comentam (com frequência) bloggers com quem estabelecem laços fortes; mas, com quem estabelecem laços fracos, só comentam quando o conteúdo do blog é valorizado. Aliás, quando o mérito de outros blogs é elevado é-lhe associada uma prática de recomendação (online e/ou offline), que permite a divulgação do blog "de boca em boca" (aumentando o colectivo).

Outro elemento de reciprocidade é a prática de linkar. O blog apresenta a possibilidade de ter uma lista de blogs favoritos (blogroll), onde cada blogger coloca link(s) de outros blogs e sites, sem limite. O blogroll pode ser tão importante que Afonso afirma: "Tu és os blogs que linkas. (...) Se é um blog sobre poesia, a grande maioria dos links que lá estão, vão ser sobre poesia”; no entanto, do seu blogroll, apenas frequenta 5 ou 6 links. Nem todos os blogs linkados são de facto os favoritos, corroborando a hipótese de Marlow (2006), de que links entre blogs são uma demonstração de interesse e leitura (dos blogs) e não representam necessariamente laços fortes. $\mathrm{O}$ acto de linkar é regulado pela assiduidade, mérito e afectividade.

Seja através de comentários ou links, com outrxs bloggers e leitorxs, aprende-se e partilha-se, porque esta relação se baseia em interesses comuns e, como diz Afonso, circula "uma espécie de transmissão de conhecimento". Diz Mariana que xs leitorxs do blog "representam pessoas que gostam das mesmas coisas que eu. (...) do mesmo estilo de fotografia, o mesmo estilo de literatura..." - esta partilha de interesses comuns é considerada uma condição para a formação de colectivos online (Herring et al. 2005).

\section{A escrita em processo com a participação do colectivo}

A natureza processual do blog, que acentua a natureza sempre processual da escrita, é extremamente valorizada nas entrevistas. Álvaro aproveita as possibilidades técnicas para analisar a sua própria escrita (verificar se repete muitas palavras) e "afinar pequenos erros". O formato virtual permite constantes alterações nos poemas, ao contrário do que se passa nos livros, que não o permitem. É a concretização do "sonho do Herberto Helder" (Álvaro), porque é "a obra em aberto, obra em contínuo" (Hélder), já que "um poema nunca está acabado”, por oposição ao livro, um "objecto acabado" (Afonso). O blog é, neste sentido, referido como ferramenta de trabalho, onde mais facilmente se pode experimentar a escrita e expandir possibilidades de

11 Por exemplo, Mariana conheceu a sua melhor amiga através do blog e Raquel fez amizades através do blog, afirmando que "na blogosfera, o mundo é pequeno", pelo facto de ter conhecido, pessoal e casualmente, um poeta-blogger, numa Feira do Livro. Diana contou com os serviços de designer de uma blogger que veio ajudar os seus tios no início de um negócio. Os amigos de Rui são poetas com quem ele interage numa lista de poesia. Liliana conheceu, através do blog, o blogger Bruno, que se tornou seu amigo e, posteriormente, ilustrou o livro de poesia que Liliana publicou. 
sentidos, "envolvendo" os textos noutros "elementos extra-literários", dando "toda uma nova roupagem à escrita" (Hélder). Por exemplo, os posts de Liliana são sempre compostos por texto, música e imagem.

Esta escrita em processo faz-se com a participação do colectivo, que tem a sua forma mais visível nos blogs colectivos. Afonso tinha um blog colectivo para "associar várias artes e nunca publicar um poema sozinho", construindo poemas a partir de fotos, quadros e/ou escultura de outrxs, ou vice-versa; e Eduardo tem um blog colectivo porque "eu, para escrever, também preciso de outras pessoas para me estimularem a escrever (...) para ter várias perspectivas”. Joana escreve textos a partir de frases de um blogger amigo que, por sua vez, escreve textos a partir de desenhos seus: "são aquelas coisas que não aconteceriam se o blog não existisse". Também pelo jogo da "ciranda" se constrói um texto colectivo: "daquilo que estás a ler, copia a página 161, 6. ${ }^{\mathrm{a}}$ linha" - e passar a outrxs bloggers.

Mas o colectivo participa de várias formas. O feedback (sobretudo através dos comentários) de outrxs bloggers e leitorxs também influencia a escrita. Por exemplo, Rui opta por reescrever poemas depois de receber comentários: "sem os leitores não podemos classificar, nem orientar, aquilo que vamos escrevendo". Rui assegura que "Se chegasse à conclusão que ninguém lia os meus poemas, possivelmente deixava de escrever". Hélder aprecia comentários que apontem gralhas aos seus poemas e, tal como Raquel e Afonso, aprecia comentários que relacionem os seus poemas com outras leituras (de poetas, livros, filmes). Ainda, Afonso aspira a que os seus poemas sejam comentados e continuados com outros poemas, "que alguém pegasse naqueles textos (...) e lhes desse continuidade". E afirma que há blogs que lhe transmitem "inspiração para ir criar alguma coisa. E isso é importante, porque aquilo é uma plataforma e é um impulsionador de diálogo".

Liliana afirma que foram os comentários positivos no blog que lhe deram confiança para publicar os seus poemas em livro, acrescentando "é importante saber se os outros gostam, o que é que dizem... é importante a opinião... dos que estão de fora, é muito importante".

Raquel fala positivamente da "sensação que alguém está a ler as tuas coisas" e, tal como Diana, usa a metáfora do blog como gaveta ${ }^{12}$ - "uma gaveta mais pública" (Diana) que "está sempre ali vazia, quando te apetecer abres e pões lá coisas" (Raquel). Eduardo diz: "raramente tenho feedback mas, pronto, é aquela ideia de que pode ser visto por mais gente do que se estiver à espera de uma edição por livro e ter possibilidade de ter um feedback.” (Eduardo).

\section{Refinamento literário}

O colectivo que participa na blogosfera literária permite o próprio refinamento da escrita (individual e colectiva). Álvaro descreve:

Em termos de poesia, [os blogs] têm feito muito, muito bem, em termos de ter a noção para onde é que se caminha. Porque os bloggers são um rebanho atento. (...) Até porque se melhora na escrita também. Porque nos obriga visualmente a ver o que está feito. Porque se um poeta está isolado numa cabana (risos) e começa a escrever, ele depois diz assim "é pá, isto é mesmo bom!". Ele não tem a noção do que os outros estão a escrever, e então pode estar a fazer igual, pode estar a fazer assim... a fazer bem todos fazem, porque cada um

12 Referência à expressão popular "escrever para a gaveta", que significa não publicar e ser esquecido. 
faz o que sente. Mas em termos de consciência de grupo, em termos de querer experimentar coisas novas, às vezes as dicas são fundamentais. É por isso que os poetas lêem também, se não, nunca liam (risos).

Por exemplo, Afonso, a partir do momento em que começou "a descobrir outros blogs", apercebeu-se que o caminho poético que estava a seguir (fotopoesia) "não [era] assim tão original”, já estava explorado. Raquel também é influenciada pelo que lê nos outros blogs de poesia, preocupando-se com a questão da variação na sua escrita em relação à escrita de outrxs poetas-bloggers:

E depois começas a ler coisas e parece que está toda a gente a escrever o mesmo e que se copiam textos uns aos outros e...sabes? E depois dá a sensação de que "Eh pá eu estou a escrever alguma coisa que já tanta gente escreveu. Para que é que eu estou a escrever isto? É mesmo perda de tempo." E então fico assim um bocado desiludida e passo, assim, agora muito tempo sem escrever nada de bom (...). [Por exemplo], toda a gente já escreveu sobre a solidão. E depois são sempre as mesmas palavras. E depois uma pessoa lê aquilo [que escreve], "eh pá de certeza que já alguém escreveu isto." E nem sequer chego a pôr aquilo, porque se depois vou pôr aquilo, vou apagá-lo p'raí daí a duas horas porque acho horrível. (Raquel)

\section{A publicação online e offline}

O blog é valorizado pelo "imediatismo na escrita e na recepção" (Eduardo), em comparação com os media impressos. É também muito valorizado o facto de ser gratuito e a liberdade e facilidade (técnica, etc) da publicação em blog - Eduardo refere-se ao blog como uma "editora-blogger". A partir do blog aparecem "sugestões e desafios, participações e trabalhos em coisas" (Álvaro).

Mas o blog também facilita a publicação no impresso (offline). Através do blog pode entrar-se em contacto com responsáveis de revistas e daí surgir a oportunidade de publicar (Afonso); isso aconteceu a Mariana que, para além de ser publicada em revista devido ao seu blog, teve, sobre si, um artigo publicado por um blogger-amigo. Liliana considera os blogs uma boa oportunidade para publicar em livro - como aconteceu com ela e com Raquel, que teve convites de editoras no seu blog (embora tenha recusado).

\section{A crítica}

Através dos blogs há oportunidade de conhecer e/ou trocar informação com ídolos. É a Sofia que escreve João Camilo, professor universitário e escritor, elogiando os poemas que leu no blog. É também um professor universitário que descobre os poemas de Joana e faz a crítica literária desses poemas. Além de Bruno, Liliana também conheceu, através do blog, uma figura pública portuguesa, que fez a apresentação do seu primeiro livro; e foi juntos que Marco, Bruno e Liliana fundaram uma tertúlia literário-cultural. Uma poeta-blogger convida Sofia, enquanto poeta, para participar numa mesa redonda num Encontro Nacional de Poetas. Rui afirma que foi através da leitura dos poemas no seu blog e do seu trabalho de escrita criativa com outros poetas da lista de poesia que elementos do Ministério da Educação o convidaram para ser professor de escrita criativa nos cursos de professores de português no estrangeiro. 


\section{Os Conflitos}

A blogosfera também é atravessada por conflitos. Estabelecem-se laços negativos com leitorxs e bloggers, nomeadamente, bloggers-plagiadorxs e leitorxs-maldizentes, que são excluídos da rede. Mariana foi alvo de plágio, tendo, durante uns tempos, optado por não colocar poemas da sua autoria. Os comentários, anónimos ou não, contendo insultos são acerrimamente criticados. Raquel já foi insultada e, durante um período de tempo, exerceu uma filtragem de comentários. $\mathrm{Na}$ caixa de comentários ocorrem conflitos literários: Liliana afirma ter tido "uma guerra com um senhor de uma revista [literária]”.

\section{REFLEXÕES FINAIS}

As redes sociais destxs poetas-bloggers estruturam, em processo, as suas identidades poéticas. Os diferentes nós e laços vão sofrendo reconfigurações ao longo das trajectórias destxs poetas-bloggers. Os laços de parentesco, laços fortes, activos e positivos, têm um papel crucial no início da "descoberta" do gosto e do interesse pela escrita, igualado ou superado em importância pelos laços discipulares, também, laços fortes, activos (enquanto partilham o espaço institucional) e positivos. Porque as identidades são então eminentemente relacionais e se baseiam no reconhecimento pelos outros e na diferenciação dos outros, os laços de parentesco e discipulares são os primeiros a interferir no modo como se constrói a identificação com a escrita. A relação com a escrita na memória dxs entrevistadxs é fundada também na relação com os livros e bibliotecas, que por vezes os une a amigxs e professorxs.

São sobretudo laços de amizade e bloguísticos (que se podem sobrepor) que proporcionam oportunidades: 1) de visibilização da escrita (publicação em revistas, leituras de poesia, participação em encontros de poetas); e 2) da sua colectivização (é com amigxs e bloggers que se fazem projectos poéticos e artísticos, blogs colectivos, listas de poesia, escrita colectiva, tertúlias poéticas, etc). São também estes laços que 3) conferem uma identidade colectiva a estxs poetas, que se sentem parte de um colectivo, construído através de práticas como "alimentar", comentar e linkar.

O blog permite uma escrita em processo com a participação do colectivo (de leitorxs, bloggers, pares, formada através do blog), facilitando a publicação online e offline, alargando o capital social e literário dxs poetas amadorxs.

Ser poeta tem que ver com a actividade em si (a escrita de poemas), e o tornar pública a sua actividade. Através de leituras públicas (no caso do Rui), através de escrever "muito em público" (como Hélder, que frequentou o mesmo café, durante anos, onde escrevia e depois oferecia os seus poemas às pessoas); mas, fundamentalmente, tornar publicada, em blog ou livro, a sua actividade poética. Embora todxs os entrevistados tenham reservas sobre a palavra poeta, considerando o seu uso desadequado ou pretensioso, xs entrevistadxs que não têm livro publicado são os que mais reservas têm. Assim, o auto-reconhecimento de uma identidade poética tem duas condições. A primeira condição é o medium em que se publica: só entrevistadxs publicadxs em livro se auto-reconhecem como poetas. A outra condição é a presença de ídolos do mundo literário impresso (e mesmo pares) na rede destas pessoas: o hetero-reconhecimento literário pelos ídolos permite o auto-reconhecimento enquanto poeta. 
É através do blog que estxs poetas amadores emergem como sujeitos (“autores”). Estes poetas amadores publicam no espaço online formas outras de representação do real. No sentido em que a blogosfera dá voz a poetas que não têm acesso aos mecanismos das instituições literárias dominantes, isto permite-nos falar da blogosfera como um espaço alternativo para a prática poética, um espaço de reformulação de poder, autoridade e legitimidade literários.

Paulo compara o estatuto identitário dos bloggers com o dos graffiters: "a nossa parede é a blogosfera”. Contudo, para este entrevistado, os bloggers não têm o mesmo estatuto artístico que os grafitters e os grafitis têm vindo a adquirir, visível, por exemplo, na designação de "arte urbana". Bem pelo contrário, Paulo conclui que "os bloggers não têm a qualidade dos grandes poetas”. Os poetas amadorxs estudados não reivindicam a blogosfera como um espaço (alternativo) de legitimidade artística. Para estxs poetas amadorxs que designei experimentais, o blog é "uma gaveta mais pública".

Apesar do potencial democrático da blogosfera na promoção de um espaço público para a voz dxs poetas, os discursos dxs poetas revelam uma representação hierárquica do livro em relação ao blog, e concepções a-históricas da qualidade da obra.

A blogosfera poética aqui analisada é constituída por poemas "contra-hegemónicos" em relação à hegemonia do cânone poético português transmitido nas escolas, e repercutido noutros mecanismos de consagração literária (desde prémios literários a publicação em grandes editoras). Nesse sentido, a blogosfera poética experimental pode ser uma "literatura menor", tal como a entendem Deleuze e Guatarri (2002: 18): a linguagem é a desterritorializada, o individual tem ligação imediata com o político, e há um agenciamento colectivo de enunciação - a literatura como linha de fuga à linguagem dos mestres (Deleuze e Guattari 2002), do cânone. Tal como a "literatura menor" não é usada para designar uma literatura específica, mas as condições revolucionárias para a literatura dentro da chamada grande literatura (canónica), também a blogosfera poética permite a circulação desta poesia experimental.

Os blogs, por vezes apesar dxs discursos dxs poetas, estão a funcionar como espaços de circulação de poéticas contra-hegemónicas. É na prática poética destxs poetas-bloggers que surge a transgressão das convenções poéticas e sociais, constituindo-se estas práticas de escrita como pesquisa epistemológica, que é sempre política, ao propor e experimentar novas formas de representar o real. A blogosfera poética alarga o espaço público para este marginalizado discurso do conhecimento - a poesia.

\section{REFERÊNCIAS BIBLIOGRÁFICAS}

Babo, Maria Augusta. 2000. «As transformações provocadas pelas tecnologias digitais na instituição literária.» Biblioteca on-line de ciências da comunicação 1-7.

Bourdieu, Pierre. 1996. As Regras da Arte: génese e estrutura do campo literário. Lisboa: Presença. Brown, Jo, Amanda J. Broderick, e Nick Lee. 2007. «Word of Mouth Communication within Online Communities: Conceptualizing the Online Social Network». Journal of Interactive Marketing 21(3):2-20.

Craig, Ailsa. 2006. The Practice of Poetry: Identity, Community and Subculture. New York University. 
Craig, Ailsa, e Sébastien Dubois. 2010. «Between Art and Money: The Social Space of Public Readings in Contemporary Poetry Economies and Careers». Poetics 38(5):441-60.

Craith, Máiréad Nic, e Laurent Sebastian Fournier. 2016. «Literary Anthropology». Anthropological Journal of European Cultures 25(1):1-8.

Deleuze, Gilles, e Félix Guattari. 2002. Kafka: Para uma literatura menor. Lisboa: Assírio \& Alvim.

DeNora, T. 1995. Beethoven and the Construction of Genius. University of California Press.

Dionísio, Maria de Lourdes, e Rui Vieira de Castro. 2005. O português nas escolas: ensaios sobre a lingua e a literatura no ensino secundário. Coimbra: Almedina.

Finnegan, Ruth. 2007. The hidden musicians: music-making in an English town. 2nd edition. Middletown, Conn: Wesleyan University Press.

George, João Pedro. 2002. O meio literário português: prémios literários, escritores e acontecimentos. Algés: Difel.

Gijón, Mario Martín. 2013. «The Blogosphere in the Spanish Literary Field. Consequences and Challenges to Twenty-First Century Literature». Hispanic Research Journal 14(4):373-84.

Granado, António, e Elizabete Barbosa. 2004. Weblogs: diário de bordo. Porto: Porto Editora.

Granovetter, Mark S. 1973. "The Strength of Weak Ties». American Journal of Sociology 78(6):1360-80.

Gregory, Helen. 2015. «Prospecting with the "Poetry Pioneers": Youth Poetry Slam and the U.K.'s WordCup». 10(3-4):1-24.

Griswold, Wendy. 1993. «Recent Moves in the Sociology of Literature». Annual Review of Sociology 19:455-67.

Heath, Sue, Alison Fuller, e Brenda Johnston. 2009. «Chasing Shadows: Defining Network Boundaries in Qualitative Social Network Analysis». Qualitative Research 9(5):645-61.

Hennion, Antoine. 2001. «Music Lovers: Taste as Performance». Theory, Culture E Society 18(5):1-22.

Herring, S. C., I. Kouper, J. C. Paolillo, L. A. Scheidt, M. Tyworth, P. Welsch, E. Wright, e Ning Yu. 2005. "Conversations in the Blogosphere: An Analysis "From the Bottom Up"». Pp. 107b-107b em Proceedings of the 38th Annual Hawaii International Conference on System Sciences. Big Island, HI, USA: IEEE.

Becker,s Howard. 1992. Art worlds. Berkeley: University of California Press.

Jenkins, Henry. 2006. Fans, Bloggers, and Gamers: Exploring Participatory Culture. NYU Press.

Latour, Bruno. 2005. Reassembling the social: an introduction to actor-network-theory. Oxford: Clarendon.

Levinson, Paul. 2012. New Nerw Media. London: Pearson.

Marlow, Cameron. 2006. «Linking without thinking: Weblogs , readership , and online social capital formation.» em International Communication Association Conference.

Nardi, Bonnie A., Diane J. Schiano, e Michelle Gumbrecht. 2004. «Blogging as Social Activity, or, Would You Let 900 Million People Read Your Diary?» P. 222 em Proceedings of the 2004 ACM conference on Computer supported cooperative work - CSCW'04. Chicago, Illinois, USA: ACM Press.

de Nooy, Wouter. 2003. «Fields and Networks: Correspondence Analysis and Social Network Analysis in the Framework of Field Theory». Poetics 31(5):305-27.

Portela, Manuel, e Rita Grácio. 2012. «Poesia em Rede: Poesia Portuguesa em Blogues e Sítios». Texto Digital 8.2:302-36.

Portugal, Sílvia. 2006. «Novas famílias, modos antigos : as redes sociais na produção de bem-estar». FEUC, Coimbra. 
Ramalho, Maria Irene. 1994. «Introdução: O Cânone nos Estudos Anglo-americanos». Pp. 1043 em $O$ cânone nos estudos anglo-americanos, editado por I. Caldeira. Coimbra: Minerva. Scott, John. 1991. Social network analysis: a handbook. Sage.

Wellman, Barry, e Stephen D. Berkowitz. 1991. «Introduction: studying social structures». Pp. 1-14 em Social Structures. A network approach. Cambridge: Cambridge University Press.

\section{"A MORE PUBLIC DRAWER": THE BLOGOSPHERE AS A COLLECTIVE SPACE OF SOCIO-POETIC PRACTICES}

Understanding the blogosphere as a collective space for socio-poetic practices, this article discusses the uses of blogs by amateur poets. Poetry as a collective art form is analyzed through the qualitative study of social networks [Qualitative Social Network Analysis] (Heath, Fuller, and Johnston 2009; Portugal 2006) of amateur poets. The author conducted interviews with fourteen people who kept an experimental poems' blog (opposed to the lyrical/confessional tradition which characterizes the Portuguese poetic canon). Blogs expand the social networks of these poet-bloggers, through new nodes and ties, and the reterritorialization of offline nodes and ties. The blogosphere mimics and amplifies some aspects of other offline collective spaces (like magazines or groups), but with singularities that derive from blogs' socio-technical possibilities. The blogosphere is permeated with tensions over literary authority/ authorship, in relation to the old media. The blogosphere impacts the production, distribution and consumption of poetry, discussed in this article.

Keywords: amateur poets, blogosphere, poetry blogs, new media, collective, qualitative social network analysis

Recebido em: 2019-08-31

Aceitado em: 2020-02-27 